\title{
Effect of Styrene Butadiene Rubber Latex on Mortar and Concrete
}

\section{Properties}

\author{
Shuyi Yao ${ }^{1,}$ a , Yong $\mathrm{Ge}^{2, \mathrm{~b}}$ \\ ${ }^{1,2}$ School of Transportation Science and Engineering, Harbin Institute of Technology, Harbin 150090, \\ China \\ âwh-lj2009@163.com, bhitbm@163.com
}

Keywords: SBR Modified Concrete; Mechanical Properties; Anti-Permeability.

\begin{abstract}
The use of styrene butadiene rubber (SBR) emulsions in concrete has been increasing in concrete construction and repair work due to its benefits to flexure strength, adhesion and impermeability. This research evaluated the influence of different contents $(0 \%, 5 \%, 10 \%, 15 \%$, and $20 \%$ by cement) of SBR on the mechanical properties and anti-permeability of the paste, mortar and concrete with the same water-to-cement ratio to analysis the SBR on the properties of them. For the mechanical properties, the compressive strength, flexure strength and elastic modulus were studied. The permeability was assessed by total charge-passed derived from rapid chloride permeability test (RCPT), all the samples were prepared and measured complying with the corresponding Chinese Industry Standard. Experimental results showed that the properties of the SBR modified concrete were associated with the corresponding properties of the SBR modified mortar and paste, and their properties changed in the same way with the incorporation of the SBR latex.
\end{abstract}

\section{Introduction:}

The use of high tensile strength materials such as fibers and rubbers to modify concrete is not new. Styrene butadiene rubber (SBR) latex, a type of high-polymer dispersion emulsion can be successfully bond to many materials, is widely used in engineering construction. A lot of researches have been done on the SBR latex modified cemented matrix. S. Natasha, M. Angelika etc. analyzed the SBR modified cement pasted and found that the polymer latex in the paste formed a continuous polymer network, and the compressive strength of latex modified paste was reduced, but the strain to failure was improved ${ }^{[1]}$. J. Schulze etc. found that the flexure strength of the mortar improved as the content of the SBR increased ${ }^{[2]}$. H Y Jiang found that SBR improved the water-proofing property of the mortar ${ }^{[3]}$. A. Mohsen analyzed the high-performance of fibrous polymer-modified concrete overlays and found that SBR polymer modified concrete could improve the toughness of the overlay concrete ${ }^{[4]}$.The properties of the SBR modified paste, mortar and concrete have been researched, however, there are few researches analysis the influence of SBR on the concrete by comparing the properties of the SBR modified paste, mortar and concrete with the same water-cement ratio and polymer content. In this paper, the mechanical property and anti-permeability of the concrete influenced by the polymer content were studied, the comparison of $15 \%$ SBR modified concrete, mortar and paste with similar mix proportion were studied to analysis the SBR latex on the properties of the concrete. It is believed that the incorporation of SBR changed the properties of the paste in the concrete and enhanced the paste-aggregate bonding strength that resulted in the final properties of the SBR modified concrete. It is useful for simplifying the SBR 
modified concrete research by analyzing the corresponding properties of the SBR modified mortar or paste. Also, it can be used to predicate the properties of the SBR modified concrete by the available SBR modified mortar properties.

\section{Experimental Section}

\subsection{Materials}

Cement used was grade 42.5 ordinary Portland cement produced by Ya Tai Cement Corp., complying with the Chinese Industry Standard GB 175-2007 with density of $3.10 \mathrm{~g} / \mathrm{cm}^{3}$. Coarse aggregate used was crushed limestone complying with the Chinese Industry Standard GB/T 14685-2001 with a gained size between $4.75 \mathrm{~mm} \sim 9.5 \mathrm{~mm}$. Sand used was river sand came from Songhua River complying with the Chinese Industry Standard GB/T14684-2001.

The admixtures used were SBR latex, high performance water reducer and anti-form agent. The SBR latex comes from Shandong Sheng De Corp. with solid content of $41 \pm 1 \%$ and $\mathrm{pH}$ of 9.0. The high performance water reducer used was UNF-5 Naphthalene water reducer came from Harbin Qiang Shi Corp. The anti-form agent used was DL-007 organ silicon air reducer came from Changzhou Zhen Tong Corp. All the admixtures used comply with the Chinese Industry Standard GB8076-2008.

\subsection{Test method and specimens}

For the experiment conducted, the test procedures followed the Chinese Industry Standard method showed in table 1 . The slump and the air volume were controlled $15 \pm 3 \mathrm{~cm}$ and $2 \pm 1 \%$ separately by vary the content of super plasticizer and anti-form agent.

To eliminate the influence of the specimens' sizes, all the specimen of the paste, mortar and concrete were made with the same size dimensions. The specimens were made cube with dimensions of $100 \mathrm{~mm} \times 100 \mathrm{~mm} \times 100 \mathrm{~mm}$ for compressive strength test and beam of dimensions of $100 \mathrm{~mm} \times 100 \mathrm{~mm} \times 300 \mathrm{~mm}$ for elastic modulus test, $100 \mathrm{~mm} \times 100 \mathrm{~mm} \times 400 \mathrm{~mm}$ for flexure strength test, and were cut into $100 \mathrm{~mm} \times 100 \mathrm{~mm} \times 50 \mathrm{~mm}$ for permeability test complying the corresponding standard separately. The conventional mortar and concrete specimens were cured in standard laboratory condition with temperature $20 \pm 2^{\circ} \mathrm{C}$ and relative humidity more than $95 \%$. The SBR modified specimens were cured in standard laboratory curing condition for the first 7 days, and then were air cured in $20 \pm 2^{\circ} \mathrm{C}$ with the relative humidity of $60 \pm 5 \%$ for the rest 21 days. The specimens were cured until $28 \mathrm{~d}$ for test. For all test results discussed in this paper, Average of three specimens was used as the final experimental result.

When evaluating the anti-permeability of mortar and concrete, the total charge-passed of the paste were also tested. However, the permeability of conventional paste was so high that had beyond the range of the instrument, the permeability of the conventional paste was not discussed in this research.

Table 1 Test and test method standard

\begin{tabular}{cc}
\hline Test name & Method \\
\hline Slump, Air volume & GB/T 50080-2002 \\
Mechanical properties & GB/T 50081-2002 \\
Total charge-passed(RCPT) & ASTM C1202-97 \\
\hline
\end{tabular}

\subsection{Mix proportions of concrete}

Concrete with $0 \%, 5 \%, 10 \%, 15 \%, 20 \%$ of SBR were prepared with the water cement ratio of 0.34 . The SBR contents were calculate by the solid quality of the SBR latex (i.e. the water in the latex was also included in the water cement ratio calculation). The same mix proportion of $15 \%$ 
SBR modified paste, mortar and concrete were designed with differences in whether containing coarse or fine aggregate. All the experimental mixed proportions designed were summarized in Table 2.

Table 2 Mix proportion designed $\left(\mathrm{kg} / \mathrm{m}^{3}\right)$

\begin{tabular}{cccccccc}
\hline $\begin{array}{c}\text { Mix } \\
\text { code }\end{array}$ & Cement & coarse & Sand & SBR latex & Water & $\begin{array}{c}\text { Super } \\
\text { plasticizer }\end{array}$ & $\begin{array}{c}\text { anti-form } \\
\text { agent }\end{array}$ \\
\hline CP & 450 & 0 & 0 & 0 & 153 & 5.4 & 0 \\
MP & 450 & 0 & 0 & 165 & 153 & 4.1 & 0.25 \\
CM & 450 & 0 & 780 & 0 & 153 & 5.4 & 0 \\
MM & 450 & 0 & 780 & 165 & 153 & 4.1 & 0.25 \\
CC & 450 & 975 & 780 & 0 & 153 & 5.4 & 0 \\
MC5 & 450 & 975 & 780 & 55 & 121 & 4.9 & 0.06 \\
MC10 & 450 & 975 & 780 & 110 & 88 & 4.5 & 0.11 \\
MC15 & 450 & 975 & 780 & 165 & 56 & 4.1 & 0.25 \\
MC20 & 450 & 975 & 780 & 220 & 23 & 3.6 & 0.44 \\
\hline
\end{tabular}

\section{Results and Discussion}

\subsection{Mechanical properties}

\subsubsection{Compressive strength}

The $28 \mathrm{~d}$ compressive strength of different contents of SBR modified concrete was shown in Fig. 1. The compressive strength of the concrete decreased as the contents of the SBR improved. The compressive strength of the conventional concrete was $51.3 \mathrm{MPa}$. As the SBR improved there was a slight reduction before the SBR content reached to $5 \%(49.9 \mathrm{MPa})$, then the compressive strength reduced sharply with the increase of SBR, and finally the reduction alleviated before the SBR content researched $20 \%$. The result was consistent with R Wang ${ }^{[5]}$ and A. Ali Abd Elkam ${ }^{[6]}$ on their polymer modified mortar and polymer modified SCC research.

Fig. 2 compared the compressive strength of conventional and 15\% SBR modified paste, mortar and concrete. Experimental results showed the compressive strength of 15\% SBR modified paste, mortar and concrete were lower than the conventional. The compressive strength reduction of SBR modified concrete due to the fact that the incorporation of the SBR latex significantly reduced the compressive of the mortar and paste, the modified paste was only $52.7 \%$ of the conventional.

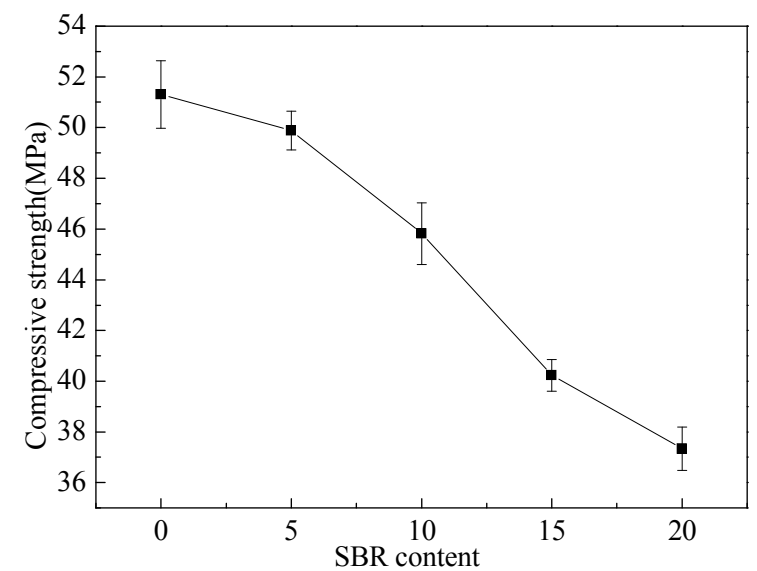

Fig.1. Influence of SBR latex on the 28d compressive strength of concrete

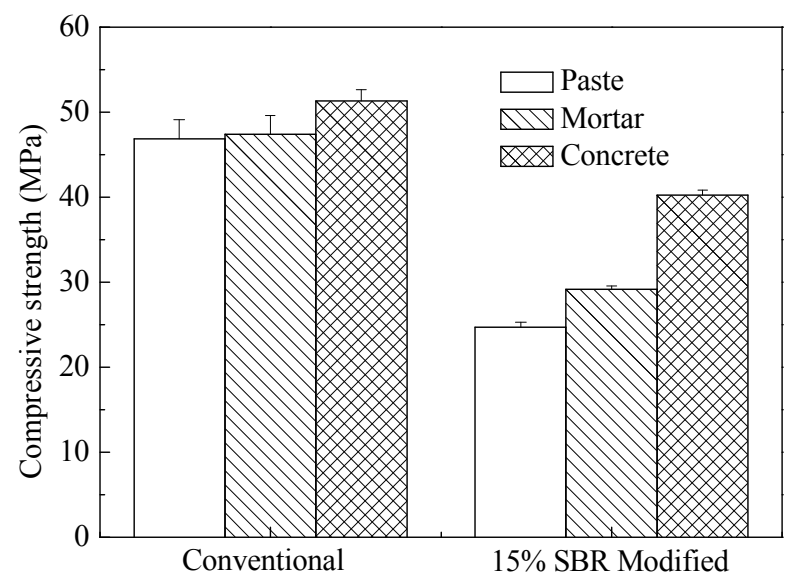

Fig.2. Compressive strength of the conventional and modified paste, mortar and concrete 


\subsubsection{Elastic modulus}

The Elastic modulus properties of the SBR modified concrete showed a similar but sharper trend than that of the compressive strength. The elastic modulus of the concrete decreased as the content of the SBR increased, as shown in figure 3. The elastic modulus of the $20 \%$ SBR modified concrete was only $37 \%$ of the conventional concrete which was lower than that the compressive strength with the same SBR content with $73 \%$ of the conventional.

Fig 4 showed the elastic modulus of the conventional and 15\% SBR modified paste, mortar and concrete. The experimental results explained the elastic modulus reduction. The incorporation of $15 \%$ SBR significantly reduced the elastic modulus of paste to its $33 \%$, although the modified mortar and concrete gained similar growth as the fine and coarse aggregate added in, the final elastic modulus of the mortar and concrete were only $30 \%$ and $41 \%$ of the conventional one's.

The reduction in elastic modulus of the SBR modified concrete due to the incorporation of SBR polymer reduced that of the paste. The polymer in the paste acted as small pores ${ }^{[7]}$ and continuous polymer network $^{[1]}$, the elastic modulus of hardened SBR was lower than the cement stone. It was easy to change its shape or disrupt under pressure. As a result, the resistance to press force and the elastic modulus reduced.

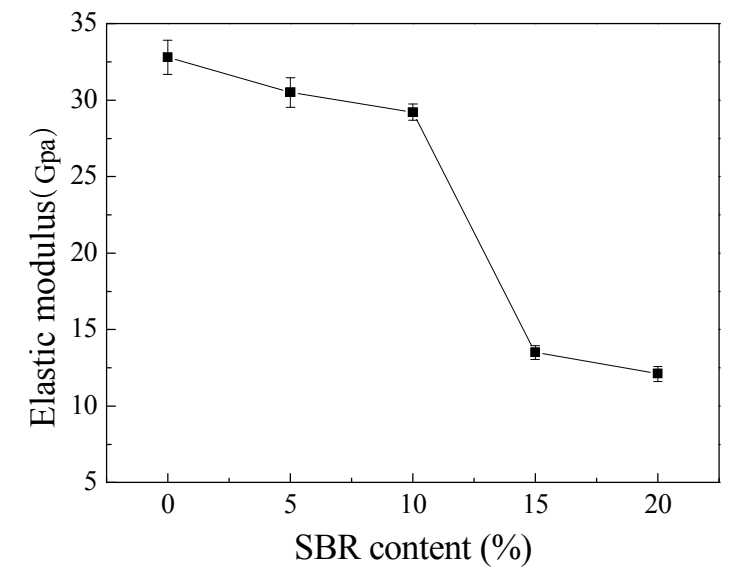

Fig. 3. Influence of SBR latex on the elastic modulus of concrete

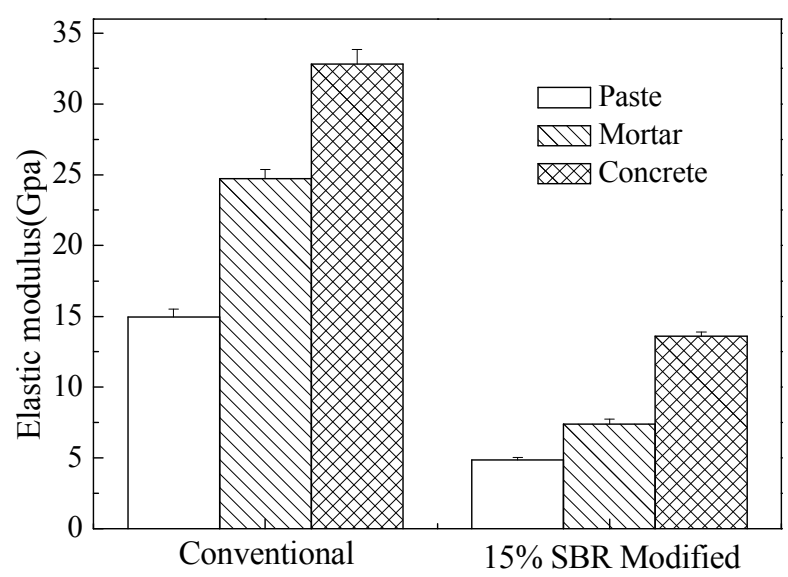

Fig. 4. Elastic modulus of conventional and modified paste, mortar and concrete

\subsubsection{Flexure strength}

Fig.5. showed the influence of SBR content on the flexure strength of the concrete. Experimental result showed that the flexure strength of the concrete increased consistently as the content of the polymer improved. It increased from $5.71 \mathrm{MPa}$ to $11.40 \mathrm{MPa}$ of $20 \% \mathrm{SBR}$ content with an increment of $99.6 \%$.

Fig 6 showed the flexure strength of the conventional and 15\% SBR modified mortar and concrete. Experimental result showed that the flexure strength of the modified mortar was $8.55 \mathrm{MPa}$, $66 \%$ higher than that of the conventional mortar of $5.15 \mathrm{MPa}$. Compared with the conventional concrete gained little flexure strength improvement, the flexure strength of the modified concrete gained 29\% increment from the modified mortar. The SBR modified concrete increased the flexure strength of the concrete with the following two reasons. The first one was that the SBR increased the flexure strength of the mortar, as shown in fig.6. The second reason was that SBR enhance the bonding of the interface of paste-aggregate of the interfacial transition zone (ITZ) between Portland cement paste and aggregate. This was accordance with the research of J. A. Rossignolo ${ }^{[8]}$ which stated that SBR reduced the thickness of ITZ as the SBR reduced the quality of $\mathrm{Ca}^{2+}$ and the cent ration of water near the coarse aggregate. 


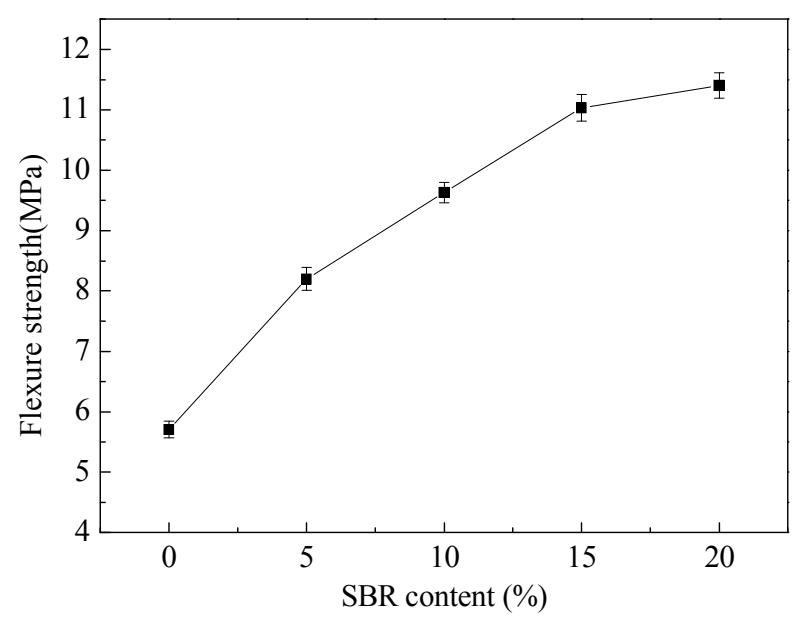

Fig. 5. Influence of SBR latex on the flexure strength of concrete

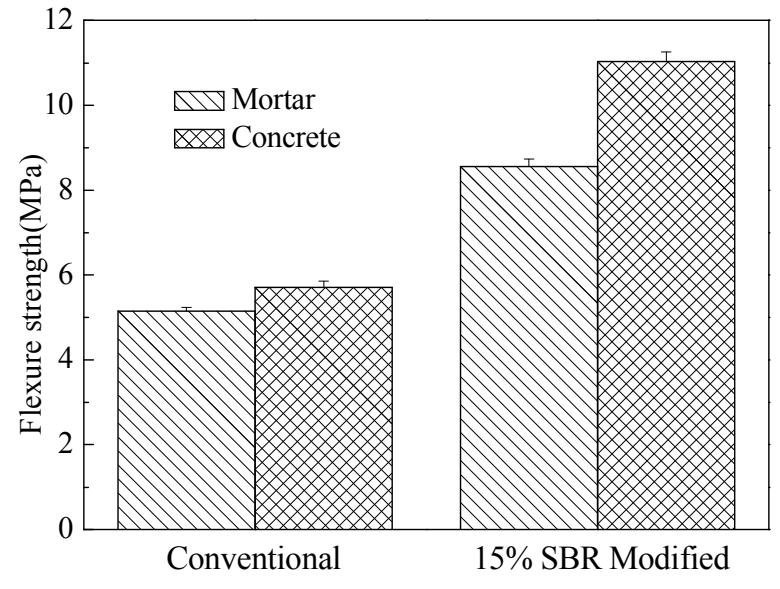

Fig. 6. Flexure strength of the conventional and modified mortar and concrete

\subsection{Permeability}

RCPT results are shown in Fig.7. The total change-passed of the conventional concrete was 1650C. The total change-passed of the concrete decreased sharply as the content of the SBR increased. The total charge-passed of the $20 \%$ SBR modified concrete reduced to $847 \mathrm{C}$, about a half of that of the conventional. Experimental result showed that the anti-permeability of the concrete improved as the content of SBR increased.

Fig.9 compared the RCPT result of the conventional and modified mortar and concrete. The total charge-passed of the conventional mortar was $6766 \mathrm{C}$ of high permeability, while that of the $15 \%$ SBR was only less than one quarter with $1530 \mathrm{C}$. The permeability of the both conventional and modified concrete were lower than the mortar. The total charge-passed were $2500 \mathrm{C}$ and $1101 \mathrm{C}$ separately. Experiment result showed that the SBR significantly reduced the permeability of the mortar, which was the main reason for the low permeability of the SBR modified concrete.

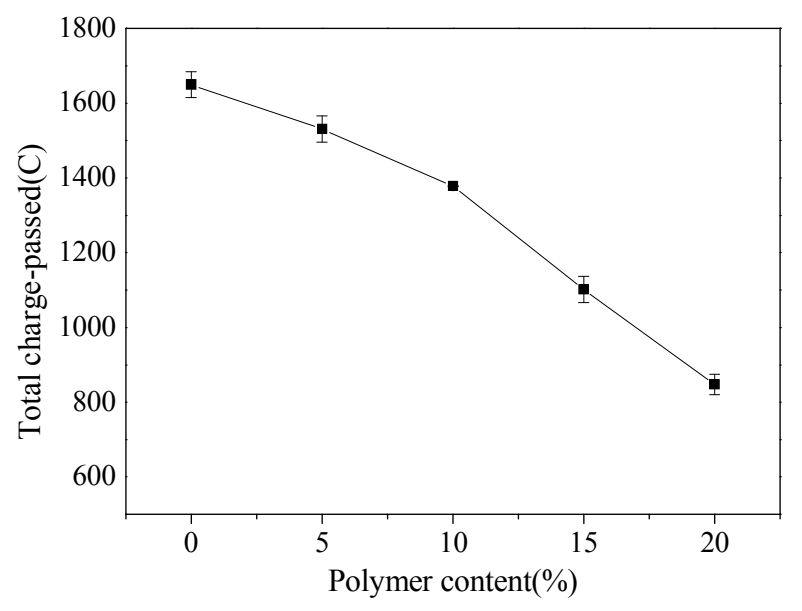

Fig. 7. RCPT results of different content of SBR modified concrete

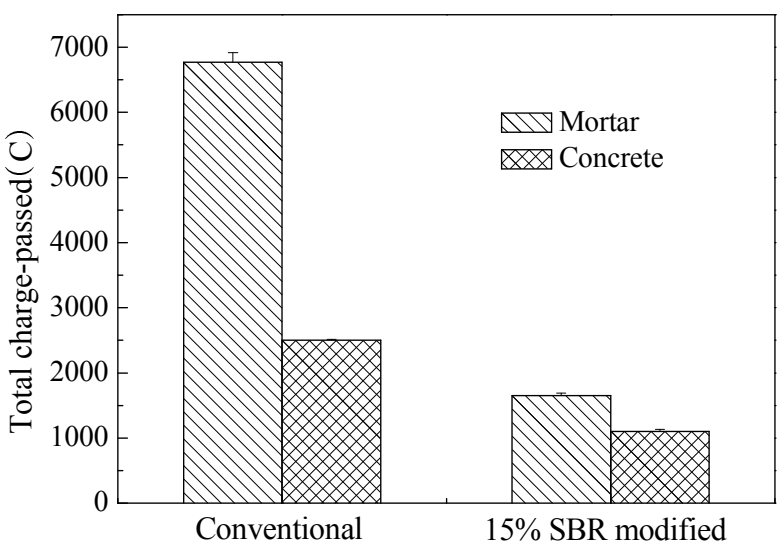

Fig. 8. RCPT result of $15 \%$ SBR conventional and modified mortar and concrete

The reduction in permeability was attributed to the fact that the SBR polymer particles were much smaller than the cement particles. They could be filled in the smaller voids of the paste and formed a monolithic film that surround the aggregates and cement particles. SBR modified mortar and concrete seldom bleeding which significantly affected the quantity of the continuous pores. 
These effects both reduced the porosity and modified the pore structure ${ }^{[9]}$. Besides, the incorporation of SBR improves the tensile strength which prevented the micro-crack also improved the impermeability of the mortar and concrete.

\section{Conclusions:}

Based on the results and discussion presented in this paper, the following conclusions can be drawn:

The incorporation of SBR significantly changed the mechanical and permeability properties of the concrete. The compressive strength and elastic modulus of the SBR modified concrete were reduced, the flexure strength was improved and the anti-permeability of the concrete increased Obtained from the rapid chloride permeability test (RCPT) with the increase of SBR content.

The mechanical and permeability properties of paste, mortar and concrete changed in the same way with the incorporation of the SBR latex. The properties of the concrete containing SBR latex were determined by influence of SBR on the corresponding properties of the hardened paste and mortar.

The change in paste-aggregate of the interfacial transition zone (ITZ) between Portland cement paste and aggregate had great influence in the properties of the SBR modified concrete, especially for improvement of the flexure strength.

\section{References:}

[1] S. Natasha, M. Angelika, F. Gary P., B. Alexander, Polymerised high internal phase emulsion cement hybrids: Macroporous polymer scaffolds for setting cements, J. Cement and Concrete Research 41(2011)443-450.

[2] J. Schulze, Influence of water-cement ratio and cement content on the properties of polymer-modified mortars, J. Cement and Concrete Research, 1999, 29-909.

[3] H. Y. Jiang, Z. X. Liu, Research of Polymer Cement Concrete, J. Journal of Wu Han University of Technology, 18 (1996): 37-38

[4] A. I. Mohsen, A. A. Mohammad, S. Hameed, High-Performance Plain and Fibrous Latex-Modified and Micro-silica Concrete Overlays, J. Journal of Materials in Civil Engineering 20(2008):742-752.

[5] R. Wang, P. M. Wang, X. G. Li. Physical and mechanical properties of styrene-butadiene rubber emulsion modified cement mortars, J. cement and concrete research 35(2005)900-906.

[6] A. Ali Abd Elkam, A. E. Abd Elmoaty, Experimental investigation on the properties of polymer modified SCC, J. Construction and Building Materials 34(2012)584-592.

[7] E. Sakai, J. Sugita, Composite mechanism of palmer modified cement, J. Cement and Concrete Research 25(1995)127-35.

[8] J. A. Rossignolo, Interfacial interactions in concretes with silica fume and SBR latex, J. Construction and Building Materials 23 (2009)817-821.

[9] M. Ramli, A. A. Tabassi. Effects of polymer modification on the permeability of cement mortars under different curing conditions: A correlational study that includes pore distributions, water absorption and compressive strength, J. Construction and Building Materials 28(2012)561-570. 